\title{
Interval Waktu Pemeliharaan Berdasarkan Reliability Centered Maintanance (RCM) Pada Kinerja Saluran Udara Tegangan Menengah (SUTM) Perusahaan Listrik Negara
}

\author{
Very Fernando ${ }^{1 *}$, Hernadewita $^{2}$, Humiras Hardi Purba ${ }^{2}$ \\ 1,2 Program Studi Magister Teknik Industri Universitas Mercu Buana \\ Jl Meruya Selatan, Kembangan, Jakarta Barat, \\ ${ }^{1 *}$ veryfernando939201@gmail.com (korespondensi) \\ 2hadeita@yahoo.com \\ ${ }^{3}$ humiras.hardi@mercubuana.ac.id
}

\section{Interval of Maintenance Based on Reliabilty Centered Maintenance on the Over Head Line of State Electricity Company}

Dikirimkan : 05, 2021. Diterima : 09, 2021. Dipublikasikan : 09, 2021

\begin{abstract}
The State Electricity Company (PLN) serves all Indonesian people from Sabang to Merauke with overhead lines and cable lines. The frequency of blackouts in an area due to disturbances in the channel. PLN seeks to suppress disturbances by carrying out maintenance, namely turning it off or without being extinguished. Medium Voltage Air Lines (SUTM) are more frequent disturbances. The worst damage happened to the conductors, Jumpers, and insulators. Damage will often occur if it is not predictable. In order to find out when damage occurs, a method based on Predictive Maintenance is used, namely maintenance based on historical disturbance data statistics. Predictive Maintenance can be realized by using Reliability Centered Maintenance (RCM). From the results of RCM calculations and statistical data on one PLN unit, there is a new value for predictive maintenance time intervals, for conductors maintenance schedule must be carried out every 2 days, Jumpers every 12 days, and isolators every 16 days before serious damage occurs and widespread blackout

Keywords - PLN; SUTM; Predictive Maintenance; Reliability Centered Maintenance
\end{abstract}

\begin{abstract}
Abstrak - Perusahaan Listrik Negara (PLN) melayani seluruh masyarakat Indonesia dari Sabang sampai Merauke dengan saluran udara dan saluran kabel. Frekuensi terjadi pemadaman pada suatu wilayah karena adanya gangguan pada saluran tersebut. PLN berupaya untuk menekan gangguan dengan melakukan pemeliharaan, yaitu dipadamkan atau tanpa dipadamkan. Saluran Udara Tegangan Menengah (SUTM) lebih sering terjadi gangguan. Kerusakan terparah ternyata terjadi pada konduktor, Jumper dan isolator. Kerusakan akan sering terjadi apabila tidak mampu diprediksi. Untuk dapat mengetahui kapan akan terjadi kerusakan digunakan metode berbasis Predictive Maintanance, yaitu pemeliharaan berdasarkan statistik data historis gangguan. Predictive Maintenance dapat terwujud dengan menggunakan Relliability Centered Maintanance (RCM). Dari hasil perhitungan RCM dan data statsik pada salah satu unit PLN, maka terdapat nilai baru intuk interval waktu pemeliharaan secara predictive, untuk konduktor harus dilakukan penjadwalan pemeliharaan setiap 2 hari, Jumper setiap 12 hari, dan Isolator setiap 16 hari sebelum terjadi kerusakan yang parah dan pemadaman meluas.
\end{abstract}

Kata kunci-PLN; SUTM; Predictive Maintenance; Reliability Centered Maintenance 
Jurnal Media

Teknik dan

Sistem Industri

\section{Pendahuluan}

Saluran Udara Tegangan Menengah (SUTM) merupakan bagian dari sistem penyaluran tenaga listrik yang berfungsi untuk menghantarkan energi listrik sampai kepada konsumen seperti pada gambar 1. Tuntutan konsumen agar listrik tetap menyala sepanjang hari tanpa gangguan membuat perusahaan penyedia listrik harus memastikan bahwa aset SUTM tetap pada kondisi yang optimal. Indikator optimal diukur berdasarkan pada pencapaian kali gangguan (downtime) setiap bulan pada SUTM.

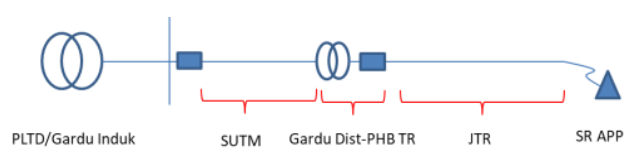

Gambar 1. Aliran Penyaluran Tenaga Listrik Sampai Kepada Pelanggan

Penyaluran energi listrik mulai dari Pembangkit Listrik Tenaga Diesel (PLTD)/Gardu Induk, dibagi ke dalam 4 Sub Aset yaitu SUTM. Gardu, Jaringan Tegangan Rendah (JTR)) dan Sambungan Rumah (SR APP). Di antara Sub Aset

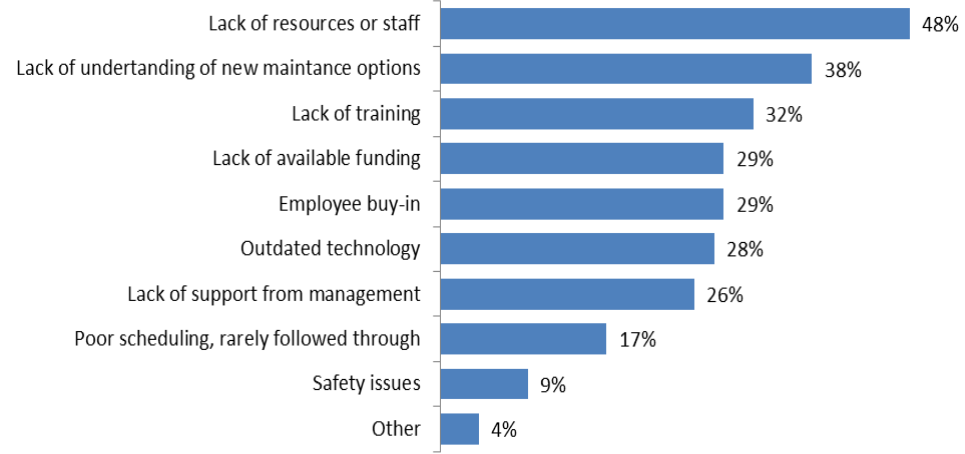

Gambar 2. Permasalahan yang terjadi pada Divisi Pemeliharaan (data diolah, 2021)
RCM adalah proses yang sistematis digunakan untuk menentukan apa yang harus diselesaikan untuk memastikan bahwa fasilitas fisik dapat memenuhi fungsi yang dirancang secara terus menerus dalam konteks operasi saat ini. RCM mengarah ke program pemeliharaan yang memfokuskan pemeliharaan preventif (PM) pada mode kegagalan tertentu yang mungkin terjadi. Setiap organisasi bisa mendapatkan keuntungan dari RCM jika kerusakannya mencapai lebih dari 20-25\% dari total beban kerja pemeliharaan [2].

Beberapa penelitian terdahulu seperti [3] melakukan penelitian pada salah satu unit PLN dengan mengambil hanya pada salah satu jenis kerusakan pada SUTM. Pada [4] mengimplementasikan RCM pada peralatan di PT Kereta API, sedangkan [5] mengimplementasikan RCM pada Unit Pembangkitan PLN. tersebut, apabila terjadi gangguan pada SUTM maka akan memberikan kontribusi pertama dan menyebabkan Severity yang luas karena SUTM berada pada Sub Aset pertama dan aliran akan terputus. Sehingga perlu dilakukan upaya yang lebih untuk memelihara Aset SUTM tersebut.

PLN Regional Sulawesi merupakan unit yang melayani kelistrikan di seluruh Pulau Sulawesi, unit ini baru sudah mengimplementasikan manajemen pemeliharaan berbasis waktu (time based maintenance), namun metode tersebut kurang efektif karena belum mampu menekan lonjakan gangguan peralatan yang sering terjadi. Menurut Facilities Maintanance Survey, [1] permasalahan dari pemeliharaan (maintenance). terlihat pada Gambar 2. bahwa kekurangan pemahaman tentang metode pemeliharaan menjadi isu yang terjadi dalam divisi pemeliharaan. Sehingga diharapkan Maintanance (RCM) mampu memberikan opsi metode pemeliharaan berdasarkan data dan fakta di lapangan. dengan menggunakan metode Relliability Centered

Tujuan dari penelitian ini adalah memberikan usulan perbaikan interval waktu pemeliharaan pada aset SUTM dengan menggunakan Reliability RCM dan usulan tersebut diharapkan menjadi dasar dalam transformasi metode Prefentive $\mathrm{Ke}$ Predictive maintenance.

\section{Metodologi Penelitian}

\section{A. Metode Reliability Centered Mainetance (RCM)}

Metodologi penelitian dilakukan dengan identifikasi masalah berdasarkan teori Mourbray [6] di mana terdapat Seven Basic Question pada RCM, yaitu menanyakan beberapa hal sebagai berikut :

- Apa fungsi dan standar kinerja terkait dari aset yang beroperasi saat ini? 
- Dengan jalan apa saja aset ini bisa gagal dalam memenuhi fungsinya ?

- Apa yang menyebabkan setiap kegagalan fungsional ?

- Apa yang terjadi pada setiap kegagalan yang timbul?

- Apa saja pengaruh dari kegagalan ini ?

- Apa yang dapat dilakukan untuk mencegah setiap kegagalan?

- Apa yang sebaiknya dilakukan bila tugas pencegahan yang sesuai tidak dapat ditemukan?

Dari Seven Basic Question RCM akan dilakukan penelitian terhadap kondisi aset (sub fasilitas) dan komponen (equipment) serta menerapkan beberapa langkah yang dijelaskan pada kajian pustaka, mulai dari penyusunan Failure Mode \& Effect Analysis (FMEA), Perhitungan RPN, Pembuatan Decision Worksheet dan sampai pada penentuan interval waktu pemeliharaan.

Dikutip dari Jurnal [4] membuat tahap demi tahap dalam penyelesaian RCM :

1. Penentuan Alat atau Equipment kritis, yaitu menentukan alat dalam sistem Saluran Udara Tegangan Menengah (SUTM) yang kritis berdasarkan jumlah atau frekuensi kerusakan setiap Equipment.

2. Menghitung nilai Risk Priority Number (RPN) pada masing-masing equipment dengan terlebih dahulu membuat tabel Failure Mode Effect Analysis (FMEA) untuk mengetahui penyebab kerusakan atau kegagalan fungsi serta dampak yang ditimbulkan. Untuk menghitung RPN didasarkan kepada Severity, Occurance, dan Detection.

3. Membuat RCM Decision Worksheet yang digunakan untuk mencari jenis pemeliharaan yang tepat dan dapat mengatasi setiap gangguan, seperti Scheduled Restoration, Schedule Discard Task dan Scheduled on Condition Task.

4. Menentukan distribusi data, dengan sudah terpilihnya Equipment kritis berdasarkan nilai RPN, maka selanjutnya adalah menentukan distribusi data Time to Repair (TTR) dan Time to Failure. (TTF) Proses penentuannya dengan membuat analisa statistik dengan membuat hipotesa apakah data kerusakan mengikuti distribusi Weilbull, Lognormal, atau Eksponensial dengan metode Least Square Curve Fitting [2].

$$
r=\frac{n \sum_{i=1}^{n} x i y i-\left(\sum_{i=1}^{n} x i\right)\left(\sum_{i=1}^{n} y i\right)}{\sqrt{\left[n \sum_{i=1}^{n} x i^{2}-\left(\sum_{i=1}^{n} x i\right)^{2}\right]\left[n \sum_{i=1}^{n} y i^{2}-\left(\sum_{i=1}^{n} y i\right)^{2}\right]}}
$$

$\mathrm{r}$ : merupakan index of fit, dimana untuk masingmasing variable memiliki formula yang berbeda sesuai jenis distribusi datanya. Penjelasannya sebagai berikut, Weibull adalah distribusi probabilitas kontiniu, Lognormali adalah distribusi variabel acak yang tersebar secara normal, dan eksponential adalah distribusi kontinyu. Ketiganya digunakan menguji reliabilitas.

a). Weilbull :

$$
\begin{array}{r}
x i=\ln t i(2) ; \\
F(t i)=\frac{i-3}{n+0,4}(3) \\
y i=\ln \left[-\ln \left[\frac{1}{1=F(t i)}\right]\right](4)
\end{array}
$$

b). Lognormal :

$$
\begin{array}{r}
x i=\ln t i(5) \\
F(t i)=\frac{i-3}{n+0,4}(6) \\
y i=Z i=\varphi^{-1}[F(t i)](7)
\end{array}
$$

c). Exponential :

$$
\begin{array}{r}
x i=t i(8) \\
F(t i)=\frac{i-3}{n+0,4}(9) \\
y i=\ln \left[-\ln \left[\frac{1}{1=F(t i)}\right]\right](10)
\end{array}
$$

$x i$ : nilai time to repair

$F(t i)$ : estimasi nilai median

$\mathrm{i}$ : baris

$\mathrm{n}$ : jumlah event gangguan

5. Melakukan Uji kesesuaian distribusi data dengan Goodness offit terhadap TTF dan TTR yang diperoleh, tujuannya untuk meyakinkan apakah pola distribusi data sesuai dengan pola distribusi tertentu agar dapat diolah lebih lanjut. Untuk poin nomor 4 dan 5 akan diuji menggunakan dengan menggunakan Minitab 19.

6. Selanjutnya adalah perhitungan parameter untuk TTF pada masing-masing equipment yang terpilih dan lulus uji kesesuaian sesuai dengan kurva distribusinya :

$$
\begin{array}{r}
b=\frac{n \sum_{i=1}^{n} x i y i-\left(\sum_{i=1}^{n} x i\right)\left(\sum_{i=1}^{n} y i\right)}{n \sum_{i=1}^{n} x i^{2}-\left(\sum_{i=1}^{n} x i\right)^{2}}(11) \\
\alpha=\bar{y}-b \bar{x}(12) \\
\beta=b(13) \\
\theta=e^{-\frac{a}{b}}(14)
\end{array}
$$

$b:$ nilai gradien

$\beta$ : Parameter Time To Failure

7. Selanjutnya adalah perhitungan parameter untuk TTR pada masing-masing equipment yang terpilih dan lulus uji kesesuaian sesuai dengan kurva distribusinya

$$
\begin{array}{r}
b=\frac{n \sum_{i=1}^{n} x i y i-\left(\sum_{i=1}^{n} x i\right)\left(\sum_{i=1}^{n} y i\right)}{n \sum_{i=1}^{n} x i^{2}-\left(\sum_{i=1}^{n} x i\right)^{2}}(15) \\
\alpha=\bar{y}-b \bar{x}(16) \\
s=\frac{1}{b}(17) \\
t_{\text {med }}=e^{-s a}(18)
\end{array}
$$


Jurnal Media

Teknik dan

Sistem Industri

8. Melakukan Perhitungan Mean Time To Failure (MTTF) dan Mean Time To Repair (MTTR) pada Equipment-Equipment kritis dengan rumus :

$$
\begin{aligned}
& \text { MTTF }=\beta \Gamma\left(1+\frac{1}{\alpha}\right) \\
& \text { MTTF }=\beta \Gamma\left(1+\frac{1}{\alpha}\right)
\end{aligned}
$$

Penentuan MTTF dan MTBF tergantung Distribusi kerusakan apakah Weilbull, Lognormal atau Exponensial.

9. Perhitungan Reliability Equipment $R(t)$ agar mengetahui probalitas kinerja dari sistem/alat untuk memenuhi fungsi yang diharapkan

$$
R(t)=e^{-\frac{t}{\theta} \beta}(21)
$$

10. Penentuan Interval pemeliharaan, yang berfungsi sebagai penentuan interval waktu pemeriksaan Equipment berdasarkan waktu operasi, dengan rumusan sebagai berikut :

a). Rata-rata operasi dalam 1 bulan, sudah ditentukan sebesar 240 Jam karena beroperasi menyalurkan listrik selama 24 Jam

b). Waktu rata-rata perbaikan

$$
\frac{1}{\mu}=\frac{M T T R}{\text { rata-rata jam kerja dalam } 1 \text { bulan }}
$$

c). Waktu rata-rata pemeriksaan

$$
\overline{\bar{t}}=\frac{\text { rata-rata sekali periksa }}{\text { rata-ratajam kerja per bulan }}
$$

d). Rata-rata kerusakan

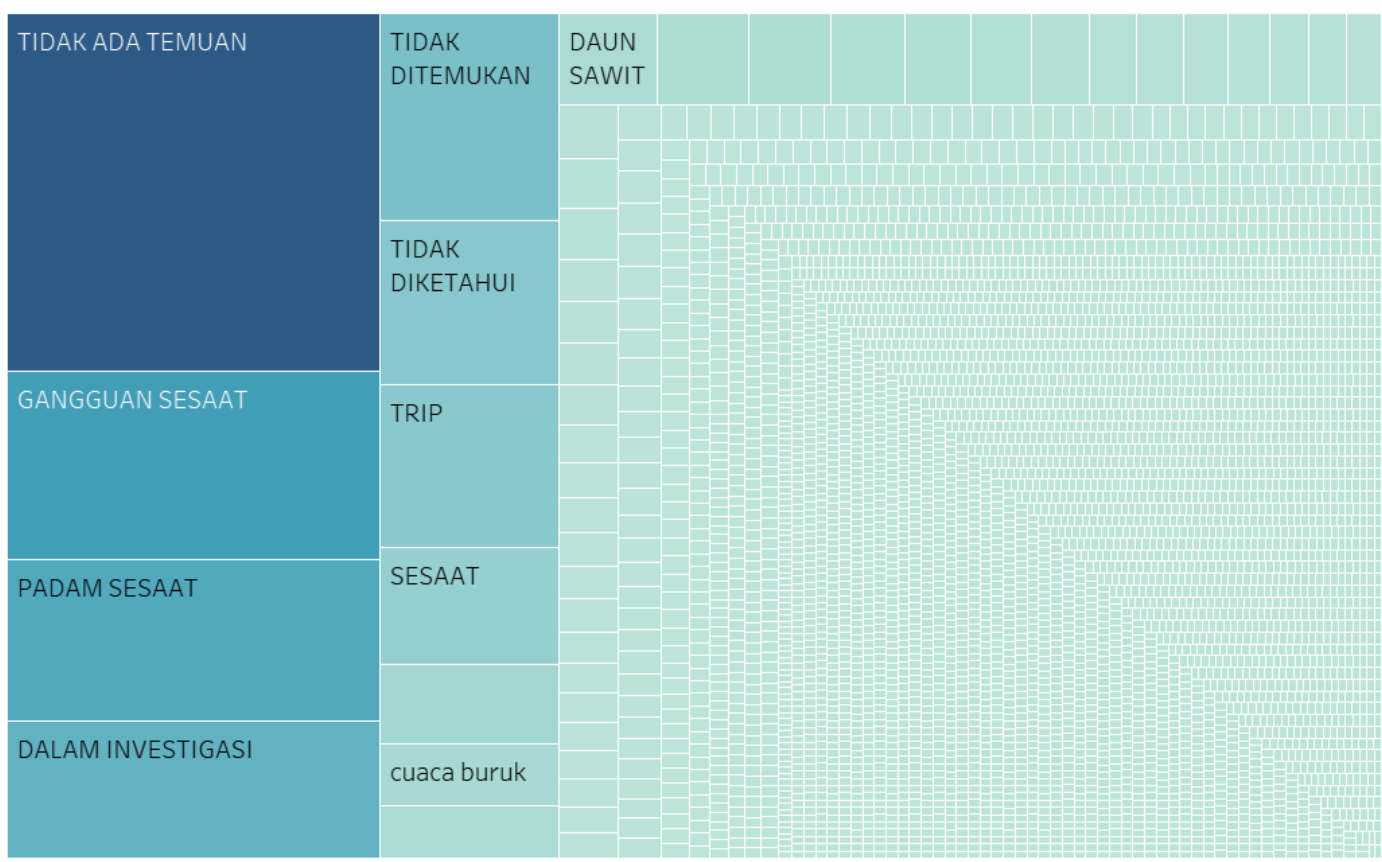

Gambar 3. Treemaps Chart Penyebab Gangguan SUTM (Data diolah, 2021) 
Dari hasil pengumpulan data kerusakan equipment SUTM yang rusak (Event Damage) dari bulan Januari sampai dengan Agustus 2019 dengan objek penelitian di seluruh unit PLN Regional Sulawesi maka didapatkan data jumlah kerusakan seperti pada Gambar 4.:

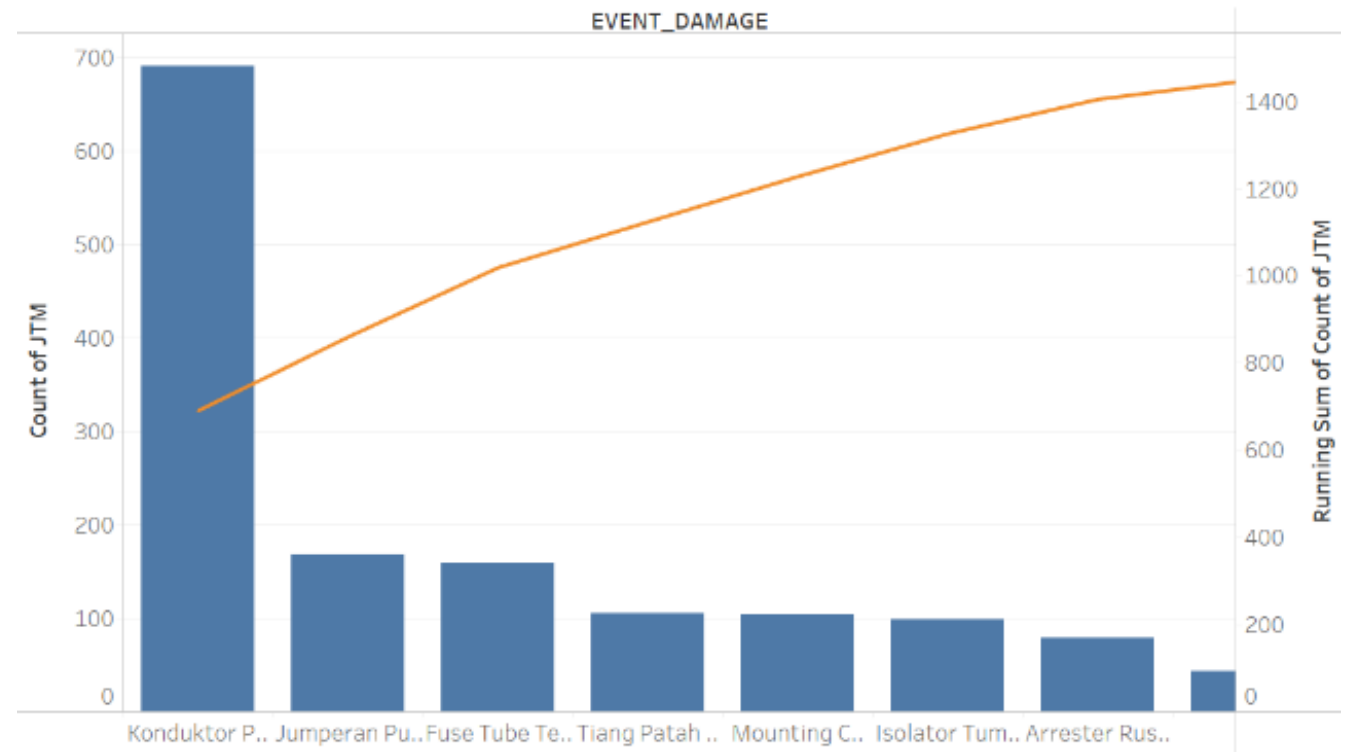

Gambar 3. Diagram Pareto Equipment Januari-Agustus 2020 (Data diolah, 2021)

\section{A. Penyusuan FMEA dan perhitungan RPN}

Untuk menentukan nilai RPN yang akurat maka dilakukan pengukuran secara kuantitatif dan kualitatif. Untuk Severity (S) dihitung secara kualitatif menggunakan seberapa banyak pelanggan yang terdampak dan bagaimana dampak terhadap equipment itu sendiri. Untuk Occurance menggunakan seberapa sering equipment terganggu. Severity akan bernilai 10 jika Pelanggan yang terdampak sebanyak 3077 Pelanggan dengan asumsi kapasitas 1 penyulang SUTM 5 MW dan 1 Pelanggan 1300 VA. Dengan menggunakan Software Tableau maka dapat ditampilkan Nilai Severity dan Occurance berdasarkan laporan Gangguan. Gambar 5. Menjelaskan alur pengambilan data dan perhitungannya.

Dengan dibuatnya FMEA dari Equipment yang menjadi Event Damage maka didapat nilai RPN tertinggi yaitu Konduktor Putus, Jumper Putus, Tiang Patah dan Isolator Pecah. Karena Tiang patah tidak termasuk dampak dari akibat suplai listrik maka tiang tidak dimasukan, Selanjutnya dilakukan pembuatan Decision Worksheet dengan hasil bahwa untuk tindakan preventif untuk mengurangi kerusakan tersebut hanya dengan melakukan inspeksi dan belum melakukan kegiatan predictive maintenance atau pemasangan sensor deteksi.

\section{B. Perhitungan Nilai TTR dan TTF}

Untuk kasus Konduktor Putus terdapat di penyulang Wundulako Kendari. Dengan bantuan Software Tableau sangat mudah untuk melihat TTR dan TTF pada setiap penyulang. Perhitungan TTR yaitu selisih antara jam padam dan jam nyala. Sementara TTF selisih kejadian hari berikutnya dengan kejadian hari sebelumnya dikurangi durasi hari sebelumnya. Karena datanya berjumlah besar maka dilakukan pengambilan data dari datawarehouse (data base PLN) dan didapat hasil TTF yang berubah setiap waktu sesuai dengan data laporan APKT. Hal ini sangat memudahkan analisa penentuan parameter berikutnya karena data yang diambil bersumber langsung dari data base yang bersifat realtime. Model pengambilan datanya tersaji pada Gambar 5. 
Jurnal Media

Teknik dan

Sistem Industri

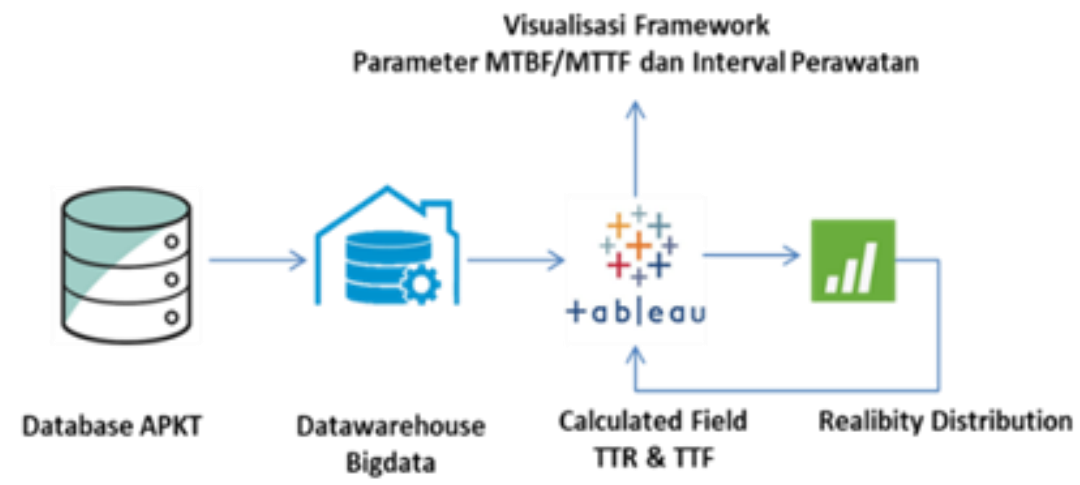

Gambar 5. Pengambilan data TTR dan TTF (Data diolah, 2021)

C. Penentuan Distribusi data dan Uji Godness Of Fit

Penentuan Distribusi data dan Uji Godness Of Fit menggunakan software Minitab 19 didapat hasil pada Tabel I :

TABEL I

PENENTUAN DISTRIBUSI DATA DAN UJI GODNESS OF FIT

\begin{tabular}{lllc}
\hline \multicolumn{1}{c}{ Equipment } & $\begin{array}{c}\text { Distrbbusi } \\
\text { TTR }\end{array}$ & $\begin{array}{c}\text { P- } \\
\text { Value>0,05 } \\
\text { Ho Diterima }\end{array}$ & $\begin{array}{c}\text { Nilai } \\
\text { Index } \\
\text { offit }\end{array}$ \\
\hline Konduktor Putus & Weibull & 0,970 & 0,970 \\
Jumper Putus & Lognormal & 0,067 & 0,940 \\
Isolator Pecah & Lognormal & 0,150 & 0,949 \\
& Distrubusi & P- & Vilai \\
Equipment & TTF & Ho Diterima & Index \\
& Weibull & 0,970 & 0,966 \\
Konduktor Putus & Lognormal & 0,150 & 0,977 \\
Jumper Putus & Lognormal & 0,127 & 0,922 \\
Isolator Pecah & & &
\end{tabular}

\section{Perhitungan MTTR dan MTTF}

Setelah didapat nilai Index Of Fit maka dilakukan perhitungan parameter TTR dan TTR menggunakan formula berdasarkan dengan jenis distribusi data dan didapat hasil pada Tabel II :

TABEL II NILAI MTTR DAN MTTF

\begin{tabular}{lllll}
\hline Equipment & $\begin{array}{c}\text { Parameter } \\
\text { TTR }\end{array}$ & $\begin{array}{c}\text { Parameter } \\
\text { TTF }\end{array}$ & MTTR & MTTF \\
\hline $\begin{array}{l}\text { Konduktor } \\
\text { Putus }\end{array}$ & 4 Jam & 6877 Jam & 9 Jam & $\begin{array}{l}\text { 13754 } \\
\text { Jam }\end{array}$ \\
$\begin{array}{l}\text { Jumper } \\
\text { Putus }\end{array}$ & 0,29 Jam & 6 Jam & 0,79 & 6 Jam \\
Isolator & 0,25 Jam & 1,12 Jam & Jam & \\
Pecah & & & Jam & 2 Jam \\
\hline
\end{tabular}

\section{PEMBAHASAN}

Hasil Akhir dari perhitungan parameter pada Tabel II. Menunjukkan nilai MTTR dan MTTF yang dilanjutkan dengan penentuan interval waktu pemeliharaan. Pertimbangan parameter tambahan seperti rata-rata jam kerja sebulan dan kinerja respon time PLN menjadi tolak ukur pengukuran. Hasil perhitungan interval dapat dilihat pada Tabel III. Dari hasil tersebut akan digabungkan dengan tabel Decision Worksheet yang telah dibuat sebelumnya. Hasil penggabungannya dapat dilihat pada Tabel III.

TABEL III

PARAMETER PENENTUAN INTERVAL WAKTU PEMELIHARAAN

\begin{tabular}{|c|c|c|c|}
\hline Parameter & $\begin{array}{c}\text { Konduktor } \\
\text { Putus }\end{array}$ & $\begin{array}{l}\text { Jumper } \\
\text { Putus }\end{array}$ & $\begin{array}{c}\text { Isolator } \\
\text { Rusak } \\
\end{array}$ \\
\hline \multicolumn{4}{|l|}{ Rata-rata Jam } \\
\hline Kerja & 208 & 208 & 208 \\
\hline Jumlah Kerusakan & 10 & 4 & 6 \\
\hline Waktu Rata-rata & 23,03 & 262,63 & 730,59 \\
\hline Perbaikan (u) & & & \\
\hline $\begin{array}{l}\text { Kinerja Respon } \\
\text { Time }\end{array}$ & 0,75 & 0,75 & 0,75 \\
\hline $\begin{array}{l}\text { Waktu Rata-rata } \\
\text { Pemeriksaan (i) }\end{array}$ & 277,33 & 277,33 & 277,33 \\
\hline Jumlah bulan & 8,00 & 8,00 & 8,00 \\
\hline $\begin{array}{l}\text { Rata-rata } \\
\text { Kerusakan (K) }\end{array}$ & 1,25 & 0,50 & 0,75 \\
\hline Frekuensi & 3,88 & 0,73 & 0,53 \\
\hline $\begin{array}{l}\text { Pemeriksaan } \\
\text { Optimal }\end{array}$ & & & \\
\hline Interval Waktu & 53,61 & 286,25 & 389,82 \\
\hline $\begin{array}{l}\text { Pemeriksaan } \\
\text { (Jam) }\end{array}$ & & & \\
\hline $\begin{array}{l}\text { (Jam) } \\
\text { Interval Waktu }\end{array}$ & & & \\
\hline Pemeriksaan & & & \\
\hline (Hari) & 2 & 12 & 16 \\
\hline
\end{tabular}

Durasi rata-rata jam kerja pada equipment konduktor paling tinggi di antara equipment lain. Hal ini senada dengan nilai pada TTR dan TTFnya. Tinggi nilai tersebut diakibatkan karena konduktor aset yang linier atau terbentang dari pusat pembangkit (gardu induk/PLTD) sampai ke pelanggan (pusat beban). Apabila terjadi gangguan di konduktor maka harus dilakukan inspeksi dari pangkal konduktor sampai ditemukan titik penyebab, hal inilah yang menyebabkan tingginya 
waktu TTR. Usulan perbaikan dari hasil perhitungan ini dapat dilakukan dengan :

1. Usahakan panjang konduktor dapat di optimalkan dengan membuat kluster yang lebih pendek, hal ini karena untuk mempersingkat durasi padam yang dirasakan oleh pelanggan berdasarkan nilai TTR .

2. Untuk membuat kluster penyulang dipasang teknologi pembatas jaringan seperti sectionalizer, recloser, dan load break switch.

3. Optimalisasi Jumlah Pegawai atau tenaga yang melakukan inspeksi pada ketiga equipment tersebut.
Usulan rentang waktu untuk dilakukan pemeliharaan pada setiap equipment dapat dilihat pada Table IV. Dan menjadi dasar jadwal pemeliharaan berdasarkan Reliability Centered Maintenance sehingga lebih efisien dibanding metode pemeliharaan sebelumnya.

TABEL IV

USULAN METODE PREDICTIVE MAINTANANCE SUTM

\begin{tabular}{|c|c|c|c|c|}
\hline No & Equipment & Jenis Kerusakan & $\begin{array}{l}\text { Jenis Pemeliharaan } \\
\text { Saat Ini }\end{array}$ & $\begin{array}{l}\text { Usulan Interval } \\
\text { Pemeliharaan }\end{array}$ \\
\hline 1 & Konduktor & Rantas & $\begin{array}{l}\text { Inspeksi } 3 \text { Bulan-6 } \\
\text { Bulan Sekali dalam } \\
\text { satu segment } \\
\text { (Preventive } \\
\text { Maintanance) } \\
\text { Inspeksi } 3 \text { Bulan-6 } \\
\text { Bulan Sekali dalam } \\
\text { satu segment } \\
\text { (Preventive } \\
\text { Maintanance) }\end{array}$ & $\begin{array}{l}\text { Inspeksi } 2 \text { Hari Sekali dalam } \\
\text { satu segment (Predictive } \\
\text { Maintance) }\end{array}$ \\
\hline 2 & Jumper & Loss Contact & $\begin{array}{l}\text { Thermovisi, ADD, } \\
\text { Ultrasound } \\
\text { (Corrective } \\
\text { Maintanance) } \\
\text { Thermovisi, ADD, } \\
\text { Ultrasound } \\
\text { (Corrective } \\
\text { Maintanance) }\end{array}$ & $\begin{array}{l}\text { Inspeksi } 12 \text { Hari Sekali } \\
\text { Menggunakan Thermovisi, } \\
\text { ADD, Ultrasound } \\
\text { (Predictive Maintanance) }\end{array}$ \\
\hline 3 & $\begin{array}{c}\text { Isolator } \\
\text { Tumpu/tarik }\end{array}$ & Pecah & $\begin{array}{l}\text { Thermovisi, ADD, } \\
\text { Ultrasound } \\
\text { (Corrective } \\
\text { Maintanance) }\end{array}$ & $\begin{array}{l}\text { Inspeksi } 16 \text { Hari Sekali } \\
\text { Menggunakan Thermovisi, } \\
\text { ADD, Ultrasound } \\
\text { (Predictive Maintanance) }\end{array}$ \\
\hline
\end{tabular}

\section{KESIMPULAN}

Berdasarkan hasil penelitian dan pembahasan dengan menggunakan metode RCM maka didapat interval waktu pemeliharaan jenis Predictive Maintanance dengan mengukur pada 3 komponen kritis berdasarkan nilai RPN. Yaitu Equipment Konduktor Putus dengan distribusi data Weibull dilakukan Inspeksi setiap 2 hari, Jumper dengan distribusi data Lognormal dilakukan inspeksi setiap 12 Hari dan Isolator dengan distribusi data Lognormal dilakukan inspeksi setiap 16 hari. Diharapkan dengan penentuan interval pemeliharaan Predictive tersebut dapat mengurangi laju kerugian akibat gangguan peralatan yang menyebabkan pemadaman disisi pelanggan.

Untuk Penelitian selanjutnya dapat menggunakan kerusakan selama 1 tahun diambil dari data base Aplikasi Pengaduan dan Keluhan Pelanggan Terpadu (APKT). Untuk mendapatkan nilai RPN yang akurat, maka laporan gangguan dari Petugas Pelayanan Teknik harus memakai Keyword standar. Untuk lebih memudahkan Manajemen dalam pengambilan keputusan Predictive Maintanance, maka dapat dilakukan

Pembuatan Dashboard menggunakan aplikasi Bussines Intelegent seperti Tableu atau Power B.I dengan menggunakan raw data yang lebih besar dan dinamis.

\section{REFERENSI}

[1] B. Vavra, "Help wanted: More training, equipment upgrades," www.plantengineering.com, 2017. https://www.plantengineering.com/articles/hel p-wanted-more-training-equipment-upgrades/.

[2] B. Yssaad, M. Khiat, and A. Chaker, "Reliability centered maintenance optimization for power distribution systems," Int. J. Electr. Power Energy Syst., vol. 55, pp. 108-115, 2014, doi: 10.1016/j.ijepes.2013.08.025.

[3] S. A. Candra and A. W. Nuruddin, "Analisa Penentuan Tindakan Perawatan Saluran Udara Tegangan Menengah (Sutm) Dengan Metode 
Jurnal Media

Teknik dan

Sistem Industri

Reliability Centered ...," Pros. SNasPPM, no. September, 2018, [Online]. Available: http://prosiding.unirow.ac.id/index.php/SNasP $\mathrm{PM} /$ article/view/160.

[4] S. T. Suwanda and M. S. T. Supriyadi, "Implementasi Metode Reliability Centered Maintenance Ii (Rcm Ii) Pada Perancangan Penjadwalan Perawatan Preventif Alat ...," Pros. ..., no. Rcm Ii, pp. 288-294, 2019, [Online]. Available: https://jurnal.teknikunkris.ac.id/index.php/sem nastek2019/article/view/286.

[5] T. Taufik and S. Septyani, "Penentuan Interval Waktu Perawatan Komponen Kritis pada Mesin Turbin Di PT Pln (Persero) Sektor Pembangkit Ombilin,” J. Optimasi Sist. Ind., vol. 14, no. 2, p. 238, 2016, doi: 10.25077/josi.v14.n2.p238258.2015 .

[6] J. Moubray, "Reliability-CentredMaintenance-2 Ebook.Pdf.” p. 418, 1997. 